ORIGINAL ARTICLE

\title{
The acute effect of different massage durations on squat jump, countermovement jump and flexibility performance in muay thai athletes
}

\author{
Ramazan Bayer ${ }^{1 \mathrm{ABCDE}}$, Özgür Eken ${ }^{2 \mathrm{ABCDE}}$ \\ ${ }^{1}$ Turgut Ozal University, Malatya, Turkey \\ 2 Inonu University, Malatya, Turkey
}

Authors' Contribution: A - Study design; B - Data collection; C - Statistical analysis; D - Manuscript Preparation; E - Funds Collection

\section{Abstract \\ Background and Study Aim}

\section{Material and \\ Methods}

Results

\section{Conclusions}

Keywords:
Muay thai is a combat sport in which the competitors kick, punch, knee, elbow and growl with their opponents. The strength of the leg muscles can increase the intensity of the kick and its flexibility is a well-known issue for this sport. Determining the most appropriate method for these issues provides important gains to the athletes. One of the methods applied to achieve these gains is acute massage applications. The aim of the study is to evaluate the acute effect of different massage times on squat jump, countermovement jump and flexibility performance.

Twelve healthy male muay thai athletes (age, $19.83 \pm 1.46$ years; height, $175.33 \pm 7.91 \mathrm{~cm}$; body mass, 65.16 $\pm 13.36 \mathrm{~kg}$ ) participated in the study, who exercised three times a week. The study consists of a single group. The study consists of 4 different massage duration protocols. These protocols consist of no massage (NM), five minutes massage (5MMSG), ten minutes massage (10MMSG) and fifteen minutes massage (15MMSG). Counter movement jump, squat jump, sitting and lying flexibility were measured after each massage period, respectively. All protocols were continued on consecutive days.

There was a significant main effect for flexibility $(F=10,872 ; p=0.00)$, countermovement jump $(F=4.719$ $\mathrm{p}=.008)$ and squat jump $(\mathrm{F}=6.262 \mathrm{p}=.002)$ performance. The best flexibility, countermovement jump and squat jump performance detected immediately after 5 MMSG was respectively $35,16 \pm 6,33 ; 37,17 \pm 4,18$ and next, 36,05 $\pm 4,68$.

As a result, it is recommended that different massage durations are effective in improving physical performance, and 5MMSG before competition is recommended for athletes and coaches to get more performance.

combat sports, passive warm up, sit and reach

\section{Introduction}

As in numerous sports, strength-endurance parameters are one of the important physical parameters that determine success in combat sports [1]. Muay Thai, recognized as the national sport of Thailand and popular all over the world, is a type of kickboxing that allows kicks, punches, knees and elbows and is expressed as the "eight limb art" [2]. As in similar combat sports with muay thai, the main technical and tactical actions involve hitting the opponent [3], and reactive power, which defines an athlete's stretchshortening cycle abilities, can be considered the basis for force generation in muay thai $[4,5]$. In order to compete at a high level in combat sports such as Muay Thai, the athlete must develop strength, endurance, muscle strength, anaerobic and aerobic abilities [6]. According to Guidetti et al., [7] strength performance is among the important indicators in defense sports. While Muay Thai athletes work to increase their striking strength, they need to improve their ability to use these strokes regularly [8]. If the time available for strength development is less than 0.3 seconds, as in Muay Thai, it is assumed that it should focus on improving the speed of strength development $[9,10,11]$. Since the rate of strength development

\footnotetext{
(c) Ramazan Bayer, Özgür Eken, 2021

doi:10.15561/20755279.2021.0603
}

represents a function of neuromuscular activation [12] and an individual's ability to accelerate objects [9], many researchers recommend ballistic training to improve this quality [13-16].

It is known that before training or competition, athletes apply different warm-up protocols in order to increase their physiological and psychological capacities [17]. Accordingly, depending on the intensity and duration, different warm up protocols provide physiological, biochemical and psychological changes in the body [18, 19]. It is stated that in addition to physical warm-up, preexercise massage can be used [20] and muscle stiffness can be reduced by lengthening the massaged muscle [21]. Massage is a physical therapy intervention with psychological advantages by increasing flexibility, muscle temperature and blood flow, reducing muscle tension and pain, and preventing tissue adhesion by using hands or an accessory on the soft tissue of the body [22, 23]. It has been determined that self-massage does not reduce muscle strength or performance, and in addition increases flexibility [24], while massage application before stretching provides greater improvements in flexibility than stretching alone [24, 25]. Hemmings et al., [26] on the other hand, examined the effects of massage on repeated boxing performance using a boxing ergometer 
and stated that there was no difference in performance between the group that received a massage before the study and the group that did not.

The contribution of knowing the acute effect of different massage times on vertical jump, squat jump and flexibility performance in Muay Thai athletes to change the perspective of trainers and athletes is very important for the future of sports. In addition, the absence of a study in the literature that measured the acute effect of different massage durations on countermovement jump, squat jump and flexibility performance in muay thai athletes further increases the importance of the study. The aim of this study is to determine the effect of different massage durations on countermovement jump, squat jump and flexibility in muay thai athletes. For this purpose, as research hypotheses; (1) It is thought that flexibility performance will be positively affected in favor of $5 \mathrm{MMSG}$.

\section{Material and Methods}

\section{Participants}

Twelve healthy male active muay thai athletes who exercise three times in a week voluntarily attended to this research (age, 19,83 $\pm 1,46$ years; height, 175,33 $\pm 7,91 \mathrm{~cm}$; body mass, $65,16 \pm 13,36 \mathrm{~kg}$ ). Muay thai athletes trained for more than two years. To be included in the study, muay thai athletes should have had the following characteristics: (a) had at least 2 years of experience in the muay thai; (b) not have any functional limitation that could interfere in the tests performance; (c) not presented any medical condition that could influence the tests; (d) maintained their regular physical activity during the course of the study. Prior to participation, all subjects were briefed on the requirements and risks involved with the study.
Parental consent was sought for subjects. The study started after the approval of the Research Ethics Committee of the institution (2021/2461). All tests and training practices were performed at the same time of the day (09.00-11.00).

Experimental Design of the Study

This study is available just one group in which was included twelve male muay thai athletes and there isn't any control group. Four different massage durations which have been applied with content for 48 hours. Twelve muay thai athletes into four different massage durations were randomly taken to exclude the cumulative effect. Throughout the familiarization session's muay thai athletes were familiarized with massage durations (NM, 5MMSG, 10MMSG, and 15MMSG). The entire massage durations carried at the same time of day $(10.00 \mathrm{am}$, to avoid the effect of diurnal variations). Each massage durations started with 5 minutes of light-intensity aerobic jogging. Counter movement jump, squat jump, sit and reach flexibility were measured respectively after each massage durations (Figure 1). This study continued approximately 10 days. All protocols continued consecutive days. Sit and reach flexibility test was administered using a specially constructed box that had a slide ruler attached to the top. After one practice trial, the best score of three trials was recorded [27]. Three trials were performed for squat and counter movement jump test (Smart Jump; Fusion Sport, Australia). For each variable, the highest value of the three attempts was used for analysis.

\section{Massage Protocols}

Before starting the massage, the massage bed was wiped using disinfectant and covered with a clean disposable cover before each massage in order to ensure a hygienic environment. The temperature in the massage

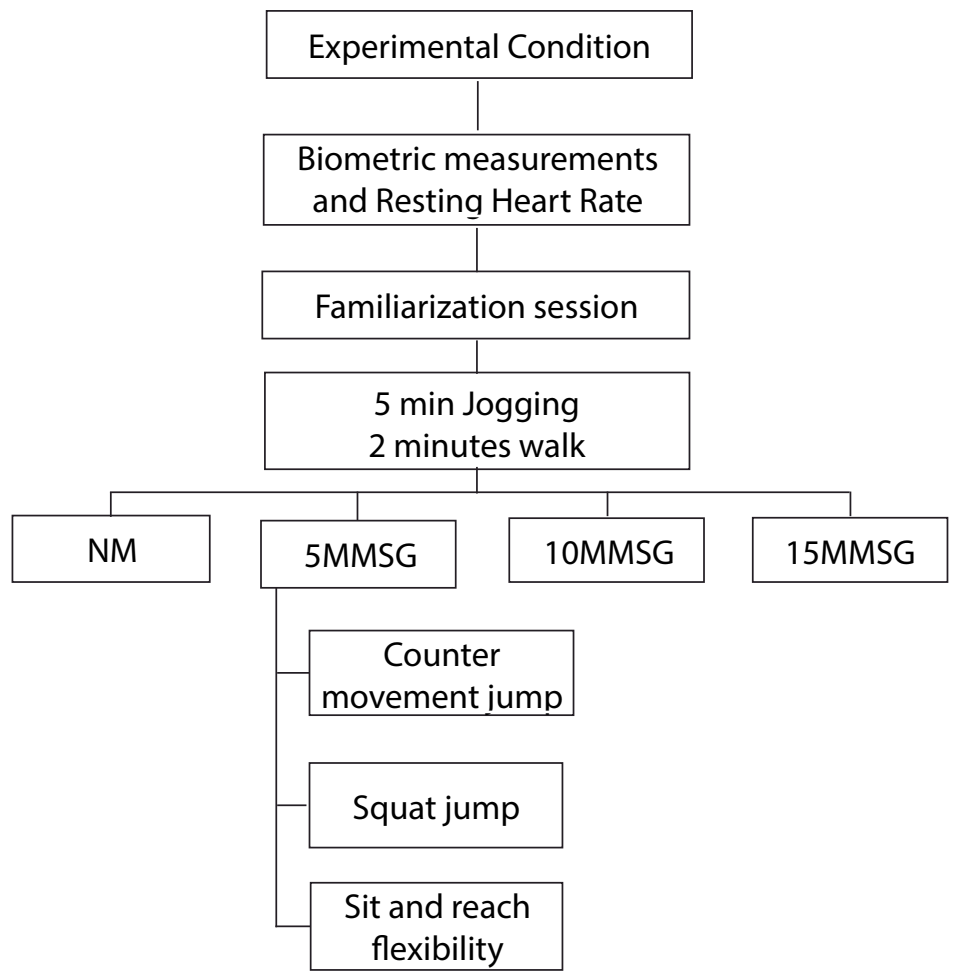

Figure 1. Experimental Design 
room was adjusted to be 22-26 before each massage. All participants were massaged by the same masseur in order to ensure consistency between massage treatments applied to different athletes. After washing his hands, the expert masseur who will apply the massage poured about $3 \mathrm{ml}$ of oil into his palms and started the massage by rubbing his hands to warm them. Aromatic oils, which affect the effect of the massage, were not used in the massage application. Approximately $30 \mathrm{ml}$ of oil was used when massaging each participant, and the massage was done in the direction of the heart and muscle fibers. During the massage, Swedish massage was used, which can increase circulation [28] and flexibility [29], and eufluorage, friction, petrissage and pressing applications were made within Swedish massage [30, 31, 32, 33]. The original technique of Swedish massage also includes the tapotement technique, but the tapotement technique was not applied during the treatments as this process may increase muscle tension [34]. There are 4 different massage protocols and durations as no massage (NM), five minutes massage (5MMSG), ten minutes massage (10MMSG) and fifteen minutes massage (15MMSG). All massage protocols started after the participants were given detailed information about the test, before the test started, the participants' maximum heart rate was determined [35]. Then, warm-up rate of jogging each individual was calculated as $30-40 \%$ according to the heart rate [36]. Participants in the study were warmed up under the control of experts. In this way, both the warm-up intensity and the warm-up differences between the participants in the study were eliminated. Participants were asked to walk for 2 minutes until their heart rate was between 110120 per minute. The massage protocols was performed for the following muscle groups (calf, quadriceps, adductor, hamstring and hip rotator) in all massage durations.

Statistical Analysis

The obtained data were analyzed in SPSS (25.0) package program. "Repeated Measures Anova" was used to determine the effect of different massage protocols on countermovement jump, squat jump and sit and reach flexibility. "Bonferroni" analysis, one of the multiple comparison tests, was used to determine which massage protocol favored the performance. Mauchly Test was used for homogeneity of variances and Greenhouse-Geisser correction factor was used to correct for variances. The significance level was chosen as $\mathrm{p}<0.05$.

\section{Results}

Figure 2 shows a comparison between flexibility, squat jump and counter movement jump values for NMSG, 5MMSG, 10MMSG and 15MMSG. It was determined that there was an increase in flexibility, squat jump and counter movement jump performance values observed after 5 MMSG $(35,16 \pm 6,33 ; 36,05 \pm 4,68 ; 37,17 \pm 4,18)$ protocol. Also flexibility $[\mathrm{F}(1,693)=10,872 \mathrm{p}=.000$, partial eta squared: ,497], squat jump $[\mathrm{F}(2.380)=6.262$ $\mathrm{p}=.002$, partial eta squared: ,363] and countermovement jump $[F(1.757))=4.719 p=.008$, partial eta squared: .300] values indicate a statistically significant difference between all protocols $(\mathrm{p}<.05)$. Performance improvement in squat jump parameters was determined as 5MMSG $(36,05 \pm 4,68)>15 \mathrm{MMSG} \quad(32,68 \pm 3,88)>10 \mathrm{MMSG}$ $(31,96 \pm 5,11)>$ NMSG $(31,91 \pm 4,96)$, from best to worst. When squat jump performances of the protocols were compared with each other, there was no statistically significant difference in any of them $(p>.05)$. Pairwise comparison, the best flexibility performance after the 5MMSG $(35,16 \pm 6,33)$ protocol was determined as $10 \mathrm{MMSG}(33,81 \pm 6,08), 15 \mathrm{MMSG}(31,90 \pm 5,87)$, NMSG $(28,70 \pm 5,63)$, respectively. When the protocols were analyzed within themselves, a statistically significant difference was found between NMMSG -5MMSG, NMSG-10MMSG, NMSG-15MMSG $(\mathrm{p}<.05)$. There is a significant difference only between 5MMSG and $15 \mathrm{MMSG}$ in counter movement jump performances $(\mathrm{p}<$ $.05)$.

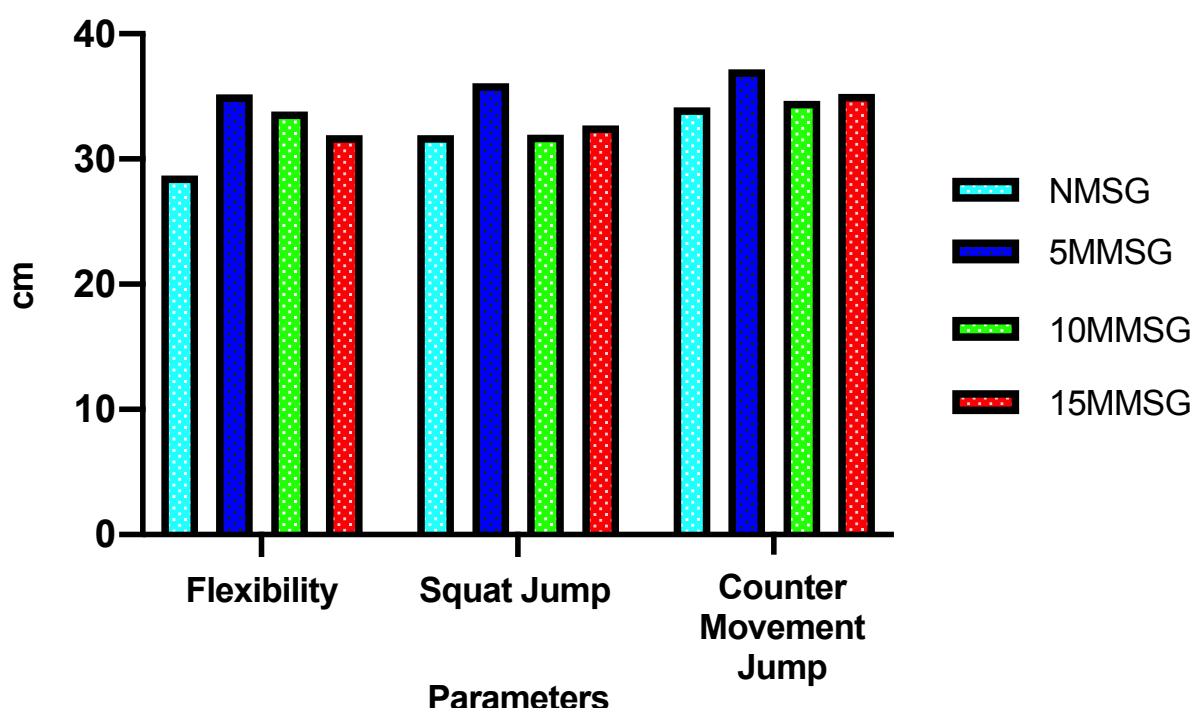

Figure 2. Flexibility, squat jump and counter movement jump performance of different massage durations 


\section{Discussion}

Coaches and sports scientists work to provide warmup and performance improvement before exercise or competition. It is thought that especially massage protocols applied before exercise or competition improve the physiological, biomechanical and psychological performance of the athletes by increasing their body temperature and range of motion. However, the optimal massage duration has not yet been determined in order to improve performance in applied massage protocols. It is important to determine the most appropriate massage duration, especially in short-term sports such as muay thai. Studies examining the effects of massage studies that provide performance improvement before exercise or competition may add originality to the literature for muay thai athletes. The aim of the study is to evaluate the effects of the most effective massage duration on flexibility, squat jump and counter movement jump performance among the different massage durations applied to muay thai athletes. It was determined that different massage durations could produce positive results on flexibility, squat jump and counter performance.

As a result of the study, it was determined that the most effective massage duration was 5MMSG. It was observed that 5MMSG had a significant increase in squat jump performance compared to the control group. When 10MMSG and 15MMSG were compared with the control group, it was observed that there was an increase in flexibility, squat jump and counter movement jump performance, while there were no significant differences between the averages of 10MMSG and 15MMSG values.

The results of the research are similar to the studies examining the effect of massage before exercise or competition. Studies have reported that massage stimulates the nervous system in the muscle tissue, increasing muscle elasticity and thus performance $[37,38]$. Sykaras et al., [39] examined the effect of 2-minute massage (e.g. effusion, petrissage, friction, tapotement, pinching and squeezing) on knee extensor peak torque after concentric/ eccentric contractions in Taekwondo athletes. As a result, it was observed that the massaged limbs performed better after intense exercise. Brooks et al., [40] reported that five minutes of manual forearm massage (including effusion and friction massage) showed significantly greater strength improvement in grip performance after 3 minutes of maximum exercise. The result of this study is similar to the results of some parameters measured in our study. Farr et al., [41] investigated the effects of massage including effusion and petrissage on muscle strength after 40 minutes of downhill walking on a treadmill in eight male participants and found that 40 minutes of downhill walking followed by 30 minutes of massage was associated with a significant benefit in strength gain.

Kargarfard et al., [42] found that 30 minutes of massage (including euphleurage, petrissage, and vibration) had positive effects on vertical jump performance in their study involving 30 male bodybuilders. Huang et al.,
[43] examined the effect of massage on the ROM of the hamstring muscle-tendinous junction and randomized ten active female participants to either 30 -second massage, 10 -second friction massage, or passive rest. As a result of the study, it was reported that there were significant increases in hip flexion ROM with 30 seconds of massage at the musculotendinous junction of the distal part of the hamstrings. However, they stated that there was no difference in passive leg tension or EMG findings. Arabaci [44] found that 10 minutes of back and 5 minutes of anterior lower extremity Swedish massage had a positive effect on sit and lie test results. This study is similar to our study in terms of reporting the positive effect of massage on flexibility performance.

It has been determined that there are studies stating that massage does not have a positive effect on strength and flexibility. For example, Hemmings et al. [45] found that massage had no positive effect on boxing power performance. Dawson et al., [46] examined the effect of repeated massage on strength gain after a half marathon and reported that massage had no effect on the rate of return to initial strength. Similarly, Dawson et al. [47] found in their study on runners that there was no significant difference between the groups in the strength indices of the athletes after the massage. Zainuddin et al., [48] stated that after eccentric elbow flexor exercise, 10-minute massage including effusion, petrissage and friction massage did not significantly improve muscle strength. In addition, studies have shown that massage does not have a positive effect on jumping performance $[49,50]$.

\section{Conclusions}

According to the results of this study, 5MMSG, 10MMSG and 15MMSG massage protocols provide positive effects on flexibility, squat jump and counter movement jump performances. It is thought that determining the most effective massage durations will save the athletes' time before the competition. As a limitation, this study did not include measurement tools that could directly identify the neurophysiological mechanisms implicated in enhancing physical performance of different massage durations, and only male muay thai athletes participated in this study. Studies that will determine the effects of different types of sports on different sports performance parameters in different massage types and massage durations to be made in the future will make significant contributions to sport performance.

\section{Acknowledgements}

We would like to thank participants in the study.

\section{Financial support}

There is no financial support.

\section{Conflict of interest}

The authors report no conflict of interest. 


\section{References}

1. SantanaJC,FukudaDH. Unconventionalmethods, techniques, and equipment for strength and conditioning in combat sports. Strength \& Conditioning Journal, 2011; 33(6):64-70. https://doi.org/10.1519/SSC.0b013e318230ff5d

2. Vail P. Muay Thai: Inventing tradition for a national symbol. Sojourn: Journal of Social Issues in Southeast Asia, 2014; 29(3): 509-553. https://doi.org/10.1355/sj29-3a

3. Platonov VN. The system of training athletes in the Olympic sport. General theory and its practical application. Kiev: Olympic Literature; 2004.

4. Bobbert MF, Gerritsen KGM, Litjens MCA, Van Soest AJ. Why is countermovement jump height greater than squat jump height? Medicine and Science in Sports and Exercise, 1996; 28: 1402-1412. https://doi.org/10.1097/00005768-199611000-00009

5. Bobbert MF, Casius LJ. Is the countermovement on jump height due to active state development? Medicine and Science in Sports and Exercise, 2005; 37: 440-446. https://doi.org/10.1249/01.mss.0000155389.34538.97

6. Buse GJ, Santana JC. Conditioning strategies for competitive kickboxing. Strength \& Conditioning Journal, 2008; 30 (4): 42-48. https://doi.org/10.1519/SSC.0b013e31817f19cd

7. Guidetti L, Musulin A, Baldari C. Physiological factors in middleweight boxing performance. Journal of Sports Medicine and Physical Fitness, 2002; 42(3):309-314.

8. Turner AN. Strength and conditioning for Muay Thai athletes. Strength \& Conditioning Journal, 2009; 31(6), 78-92. https://doi.org/10.1519/SSC.0b013e3181b99603

9. Schmidtbleicher D. Training for power events. In: Komi PV., ed. Strength and Power in Sport. London, England: Blackwell Scientific; 1992. P.381-395.

10.Newton RU, Kraemer WJ. Developing explosive muscular power: Implications for a mixed methods training strategy. Strength \& Conditioning Journal, 1994; 16: 20-31. https://doi.org/10.1519/1073-6840(1994)016<0020:DEMPI $\mathrm{F}>2.3 . \mathrm{CO} ; 2$

11.Zatsiorsky VM, Kraemer WJ. Science and Practice of Strength Training. Champaign, IL: Human Kinetics; 2006.

12.Sale DG. Neural adaptation to strength training. In: Komi PV, ed. Strength and Power in Sport (2nd ed.). London, England: Blackwell Scientific; 2993. P.249-265.

13.Hakkinen K, Komi PV, Tesch PA. Effect of combined concentric and eccentric strength training and detraining on force-time, muscle fiber and metabolic characteristics of leg extensor muscles. Scandinavian Journal of Medicine \& Science in Sports, 1981; 3: 50-58.

14.Hakkinen K, Komi P, Alen M. Effect of explosive type strength training on isometric force- and relaxation-time, electromyographic and muscle fiber characteristics of leg extensor muscles. Acta Physiologica Scandinavica, 1985; 125: 587-600. https://doi.org/10.1111/j.1748-1716.1985.tb07759.x

15.Behm DG, Sale DG. Velocity specificity of resistance training. Sports Medicine, 1993; 15: 374-388. https://doi.org/10.2165/00007256-199315060-00003

16.Haff GG, Stone MH, O’Bryant HS, Harman E, Dinan C, Johnson R, Han KH. Force-time dependent characteristics of dynamic and isometric muscle actions. Journal of Strength and Conditioning Research, 1997; 11: 269-272. https://doi.org/10.1519/00124278-199711000-00014

17.Faigenbaum AD, Bellucci M, Bernieri A, Bakker B, Hoorens K. Acute Effects of Different Warm-up Protocols on Fitness
Performance in Children. J Strength Cond Res, 2005;19:376. https://doi.org/10.1519/R-15344.1

18.Bishop D. Warm Up I: Potential Mechanisms and the Effects of Passive Warm Up on Exercise Performance. Sports Medicine, 2003;33:439-54. https://doi.org/10.2165/00007256-200333060-00005

19.Bishop D. Warm Up II: Performance Changes Following Active Warm Up and How to Structure the Warm Up. Sports Medicine, 2003;33:483-98. https://doi.org/10.2165/00007256-200333070-00002

20.Tessier DG. Sports Massage: An Overview. Athletic Therapy Today, 2005; 10(5): 67-69. https://doi.org/10.1123/att.10.5.67

21.Sullivan SJ, Williams LR, Seaborne DE, Morelli M. Effects of massage on alpha motoneuron excitability. Physical Therapy, 1991; 71(8): 555-560. https://doi.org/10.1093/ptj/71.8.555

22.Kuruma H, Takei H, Nitta O. Effects of myofascial release and stretching technique on range of motion and reaction time. Journal of Physical Therapy Science, 2013; 25:169-171. https://doi.org/10.1589/jpts.25.169

23.Zhong H, Wang C, Wan Z, Lei J. The possible mechanisms of massage therapy. Biomedical Research-tokyo. 2019;30:1-6.

24.Cheatham SW, Kolber MJ, Cain M, Lee M. The effects of self-myofascial release using a foam roll or roller massager on joint range of motion, muscle recovery, and performance: A systematic review. International Journal of Sports Physical Therapy, 2015; 10(6), 827-838.

25.Capobianco RA, Almuklass AM, Enoka RM. Manipulation of sensory input can improve stretching outcomes. European Journal of Sport Science, 2018; 18(1): 83-91. https://doi.org/10.1080/17461391.2017.1394370

26.Hemmings B, Smith M, Graydon J, Dyson R. Effects of massage on physiological restoration, perceived recovery and repeated sports performance. British Journal of Sports Medicine, 2000; 34 (2):109-114. https://doi.org/10.1136/bjsm.34.2.109

27.Lemmink KA, Kemper HC, Greef MH, Rispens P, Stevens M. The validity of the sit-and-reach test and the modified sit-andreach test in middle-aged to older men and women. Research Quarterly for Exercise and Sport, 2003; 74(3): 331-336. https://doi.org/10.1080/02701367.2003.10609099

28.Callaghan MJ. The role of massage in the management of the athlete: a review. British Journal of Sports Medicine, 1993; 27 (1):28-33. https://doi.org/10.1136/bjsm.27.1.28

29. Sullivan KM, Silvey DB, Button DC, Behm DG. Rollermassager application to the hamstrings increases sit-andreach range of motion within five to ten seconds without performance impairments. International Journal of Sports Physical Therapy, 2013;8:228-236.

30.Weerapong P, Hume PA, Kolt GS. The mechanisms of massage and effects on performance, muscle recovery and injury prevention. Sports Medicine, 2005; 35(3): 235-256. https://doi.org/10.2165/00007256-200535030-00004

31.Açak M, Öncü EH. Step by Step Massage Instruction. Malatya: Size Chart; 2006.

32.Jelvéus A. Integrated Sports Massage Therapy A Comprehensive Handbook. Elsevier Ltd.; 2011.

33.Gürkan A. Sports Massage. Iğdır University Journal of Sport Sciences, 2018; 1(1):24-8.

34.de Oliveira FR, Gonçalves LCV, Borghi F, da Silva LGRV, Gomes AE, Trevisan G, de Souza AL, Grassi-Kassisse DM, de Oliveira Crege DRX. Massage therapy in cortisol circadian rhythm, pain intensity, perceived stress index and quality 
of life of fibromyalgia syndrome patients. Complementary Therapies in Clinical Practice, 2018; 30: 85-90. https://doi.org/10.1016/j.ctcp.2017.12.006

35.Tanaka H, Monahan KD, Seals DR. Age-predicted maximal heart rate revisited. Journal of the American College of Cardiology, 2001; 37: 153-156.

36.Karvonen MJ, Kentala E, Mustala O. The effects of training on heart rate: a longitudinal study. Annales Medicinae Experimentalis et Biologiae Fenniae, 1957; 35: 307-315.

37.Kokkonen J, Nelson AG, Cornwell A. Acute muscle stretching inhibits maximal strength performance. Research Quarterly for Exercise and Sport, 1998; 69(4):411-5. https://doi.org/10.1080/02701367.1998.10607716

38.Nelson AG, Kokkonen J. Acute ballistic muscle stretching inhibits maximal strength performance. Research Quarterly for Exercise and Sport, 2001; 72(4):415-9. https://doi.org/10.1080/02701367.2001.10608978

39.Sykaras E, Mylonas A, Malliaropoulos N, Zakas A, Papacostas E. Manual massage effect in knee extensors peak torque during short-term intense continuous concentriceccentric isokinetic exercise in female elite athletes. Isokinetics and Exercise Science, 2003; 11(3):153-157. https://doi.org/10.3233/IES-2003-0142

40.Brooks CP, Woodruff LD, Wright LL, Donatell R. The immediate effects of manual massage on power-grip performance after maximal exercise in healthy adults. Journal of Alternative \& Complementary Medicine: Research on Paradigm, Practice, and Policy, 2005;11:1093-101. https://doi.org/10.1089/acm.2005.11.1093

41.Farr T, Nottle C, Nosaka K, Sacco P. The effects of therapeutic massage on delayed onset muscle soreness and muscle function following downhill walking. Journal of Science and Medicine in Sport, 2002;5:297-306. https://doi.org/10.1016/s1440-2440(02)80018-4

42.Kargarfard M, Lam ETC, Shariat A, Shaw I, Shaw BS, Tamrin SBM. Efficacy of massage on muscle soreness, perceived recovery, physiological restoration and physical performance in male bodybuilders. JournalofSports Sciences, 2016;34:1-7. https://doi.org/10.1080/02640414.2015.1081264

43.Huang SY, Di Santo M, Wadden KP, Cappa DF, Alkanani $T$, Behm DG. Short-Duration massage at the hamstrings musculotendinous junction induces greater range of motion. The Journal of Strength \& Conditioning Research, 2010;24:1917-24. https://doi.org/10.1519/JSC.0b013e3181e06e0c

44.Arabaci R. Acute effects of pre-event lower limb massage on explosive and high speed motor capacities and flexibility. Journal of Sports Science and Medicine, 2008; 7(4): 549.

45.Hemmings B, Smith M, Graydon J, Dyson R. Effects of massage on physiological restoration, perceived recovery, and repeated sports performance. British Journal of Sports Medicine, 2000;34:109-14. https://doi.org/10.1136/bjsm.34.2.109

46.Dawson LG, Dawson KA, Tiidus PM. Evaluating the influence of massage on leg strength, swelling, and pain following a half- marathon. Journal of Sports Science \& Medicine, 2004;3:37-43.

47.Dawson KA, Dawson L, Thomas A, Tiidus PM. Effectiveness of regular proactive massage therapy for novice recreational runners. Physical Therapy in Sport, 2011;12:182-7. https://doi.org/10.1016/j.ptsp.2011.02.007

48.Zainuddin Z, Newton M, Sacco P, Nosaka K. Effects of massage on delayed-onset muscle soreness, swelling, and recovery of muscle function. Journal of Athletic Training, 2005;40:174.

49.Jönhagen S, Ackermann P, Eriksson T, Saartok T, Renström PA. Sports massage after eccentric exercise. The American Journal of Sports Medicine, 2004; 32(6):1499-1503. https://doi.org/10.1177/0363546503262196

50.Delextrat A, Calleja-González J, Hippocrate A, Clarke ND. Effects of sports massage and intermittent coldwater immersion on recovery from matches by basketball players. Journal of Sports Sciences, 2013; 31(1):11-19. https://doi.org/10.1080/02640414.2012.719241

\section{Information about the authors:}

Ramazan Bayer; (corresponding author); https://orcid.org/0000-0002-2161-5886; rmznbayer@gmail.com; Turgut Ozal University, Malatya, Turkey.

Özgür Eken; https://orcid.org/0000-0002-5488-3158; ozgureken86@gmail.com; Faculty of Sport Sciences, Department of Physical Education and Sport Teaching, Inonu University, Malatya, Turkey.

\section{Cite this article as:}

Bayer R, Eken Ö. The acute effect of different massage durations on squat jump, countermovement jump and flexibility performance in muay thai athletes. Physical Education of Students, 2021;25(6):353-358. https://doi.org/10.15561/20755279.2021.0603

This is an Open Access article distributed under the terms of the Creative Commons Attribution License, which permits unrestricted use, distribution, and reproduction in any medium, provided the original work is properly cited http://creativecommons.org/licenses/by/4.0/deed.en

Received: 01.10.2021

Accepted: 03.11.2021; Published: 30.12.2021 